\title{
Pamuklu Kumaşa Antibakteriyel Bitim Uygulaması
}

\author{
Numan Harımdar ${ }^{1 *}$, Feyza Akarslan ${ }^{2}$ \\ 1 Süleyman Demirel Üniversitesi, Mühendislik Fakültesi, Tektil Mühendisliği Bölümü, Isparta, Türkiye (ORCID: 0000-0000-0000-0000) \\ ${ }^{2}$ Süleyman Demirel Üniversitesi, Mühendislik Fakültesi, Tektil Mühendisliği Bölümü, Isparta, Türkiye (ORCID: 0000-0000-0000-0000)
}

(İlk Geliş Tarihi 13 Ocak 2020 ve Kabul Tarihi 22 Şubat 2020)

(DOI: $10.31590 /$ ejosat.652139)

ATIF/REFERENCE: Harımdar, H. \& Akarslan, F. (2020). Pamuklu Kumaşa Antibakteriyel Bitim Uygulaması. Avrupa Bilim ve Teknoloji Dergisi, (18), 142-147.

\begin{abstract}
$\ddot{O} \mathbf{z}$
Toplumsal alanlarda ve medikal alanda kullanılan tekstil materyalleri üzerinde bakteri ve mantarlar gelişebilmektedir ve bunlar insan sağlığı açısından tehlike arz edebilmektedir. Mikroorganizmaların neden olduğu enfeksiyona dayalı hastalıklar ve ölümler, mikroorganizmalar yüzünden giysilerde oluşan istenmeyen koku ve lekeler antibakteriyel tekstil ürünlerinin önemini arttırmıştır. Bunun yanında sentetik maddeler ve ağır metaller ile antibakteriyel özellik kazandırılan tekstil materyallerine şüphe ile bakılmaktadır. Bu yüzden doğal tıbbi ve aromatik bitkilere olan ilgi gün geçtikçe artmaktadır.

Bu çalışmada, özellikle ülkemizde çöpe atılan veya hayvan yemi olarak kullanılan üzüm çekirdeği üzerine çalışma yapılmıştır. TÜIKK verilerine göre ülkemizde 2018 yılında şaraplık üzüm üretimi yaklaşık 464 bin tondur. Gelişmiş birçok ülkede çevre dostu ve doğal bitkisel esaslı üzüm çekirdekleri sahip oldukları zengin yağ asitleri, tokoller, fenol bileşikleri ve steroller gibi birçok farklı alanda kullanılabilmektedir. Şarap üretimi sırasında açığa çıkan cibre (üzüm çekirdeği, salkım ve üzüm kabuğu), sahip olduğu antioksidan, antimikrobiyel, antiinflamatuvar ve antikarsinojenik özelliklere rağmen yıllarca hak ettiği değeri görmemiştir. Fakat son yıllarda üzüm çekirdeği yağı üretimi, üzüm çekirdeği tozu üretimi gibi faaliyetler hayata geçmektedir. Bu çalışmada üzüm çekirdeğinin sahip olduğu bilinen antimikrobiyel özelliğinin tekstil alanında kullanımı üzerine çalışma yapılmıştır. Tekstil alanında kullanılan antibakteriyel madde ve yöntemler insan sağlığına ve çevreye zararlı etkileri olabileceği konusunda endişe duyulmaktadır. Bu nedenle son y1llarda çevre dostu ve doğal bitkisel esaslı antibakteriyel maddelerin eldesi ve tekstil uygulamalarına olan ilgi gün geçtikçe artmaktadır.

Bu çalışmada çevre dostu ve doğal bitkisel esaslı üzüm çekirdekleri, toz haline getirilerek extraksiyon işlemine tabi tutularak içindeki fenolik bileşikler elde edilmiştir. Daha sonra extraksiyon ürünündeki fenolik bileşik tayini HPLC cihazı ile yapılmış ve emdirme yöntemi ile \%100 pamuklu tekstil mamulüne aplike edilmiştir. Kurutma ve fiksaj işlemi yapıldıktan sonra kumaşın antibakteriyel testleri AATCC 147 antibakteriyel test metodu ile yapılmıştır. Yapılan testler sonucunda antibakteriyel bitim işlemi gören kumaşın biyostatik yapıya sahip antibakteriyel özellik kazandığı görülmüştür.
\end{abstract}

Anahtar Kelimeler: Antibakteriyal Tekstiller, Pamuklu Kumaş, Fenolik Bileşikler

\section{Cotton Fabric Antibacterial Finishing Application}

\begin{abstract}
Bacteria and fungi can develop on textile materials used in social and medical fields and these can be dangerous for human health. Infection-related diseases and deaths caused by microorganisms, unwanted odors and stains on clothes caused by microorganisms have increased the importance of antibacterial textile products. In addition, synthetic materials and heavy metals and antibacterial properties of textile materials are considered with doubt. Therefore, interest in natural medicinal and aromatic plants is increasing day by day. In this study, especially grape seed which is thrown in our country or used as animal feed has been studied. According to TUIK data, wine grape production in our country in 2018 is approximately 464 thousand tons. In many developed countries, environmentally
\end{abstract}

\footnotetext{
* Sorumlu Yazar: Süleyman Demirel Üniversitesi Üniversitesi, Mühendislik Fakültesi, Tektil Mühendisliği Bölümü, Isparta, Türkiye, ORCID: 00000000-0000-0000, numanharimdar 20@hotmail.com
} 
friendly and natural vegetable based grape seeds can be used in many different fields such as rich fatty acids, tocols, phenol compounds and sterols. Despite the antioxidant, antimicrobial, antiinflammatory and anticarcinogenic properties it possesses, the gypsum (grape seed, bunch and grape peel) released during the production of wine has not received its deserved value for years. However, in recent years, activities such as grape seed oil production and grape seed powder production are realized. In this study, the use of the antimicrobial property of grape seed in textile field has been studied. There is concern that antibacterial substances and methods used in the textile field may have harmful effects on human health and the environment. Therefore, in recent years, the production of environmentally friendly and natural plant based antibacterial substances and interest in textile applications are increasing day by day. In this study, phenolic compounds were obtained by extracting the environmentally friendly and natural plant based grape seeds into powder. Then the phenolic compound in the extraction product was determined by HPLC and applied to $100 \%$ cotton textile by impregnation method. After drying and fixing process, antibacterial tests of the fabric were carried out with AATCC 147 antibacterial test method. As a result of the tests, it has been observed that the fabric treated with antibacterial lacquer gains antibacterial properties with its biostatic structure.

\section{Keywords: Antibacterial Textiles, Cotton Fabric, Phenolic Compound}

\section{Giriș}

Pek çok tekstil malzemesi sürekli olarak oteller, çocuk yuvaları ve hastaneler gibi toplu yaşam alanlarında tekrar tekrar kullanılmaktadır. Bu malzemeler üzerinde üreyebilen mikroorganizmalar sebebiyle enfeksiyona dayalı hastalıklar ve ölümler meydana gelebilmektedir. Aynı zamanda mikroorganizmalar ile temas eden bu giysiler enfeksiyona dayalı hastalıkların yayılmasına yol açabilmektedir. Bu sebeple, bulaşıcı mikroorganizmalar tüketici sağlı̆̆ için potansiyel bir tehdit oluşturabilmektedir. Bu olumsuzluklara mikroorganizmaların çoğalarak büyümesi de eklenirse, tüketiciler için çok ciddi problemler ortaya çıkabilmektedir (Süpüren, 2006). Ayrıca günümüzde tüketicilerin kalite bilinçlerinin artmasından dolayı tekstiller için daha çok sağlı ve konfor konuları üzerine bir beklenti olmaktadır. Mikroorganizmalar yüzünden giysilerde oluşan istenmeyen koku ve lekeler antibakteriyel tekstil ürünlerinin önemini arttırmıştır (Altınok, 2008). Bunun sonucu olarak, çeşitli endüstri alanlarında uzun süreden beri kullanılan ve mikroorganizmaların tekstil yüzeylerinde yerleşmelerini veya çoğalabilmelerini önlemek amacıyla yapılan antimikrobiyel uygulamalar hızla yaygınlaşmaktadır (Orhan, 2007).

Antibakteriyel maddeler incelendiğinde, ilk olarak karşımıza eski zamanlardan beri bilinen gümüş ve çinko gibi bazı metal uygulanmaları çıkmaktadır. Bu maddeler nanoboyutta da karşımıza çıkmaktadır. Gümüşün bakterilere karşı oldukça etkili bir metal oluşmasının yanında, uygulama miktarına bağlı olarak fiyatının yüksek olması açısından dezavantajlıdır. Çinko metali ise gümüş ile karşılaştırıldığında, antibakteriyel özellik açısından etkinliği düşük ancak fiyat açısından daha caziptir. Günümüz sıkı rekabet şartlarında geleneksel tekstil üretimine ek olarak yeni özellikli materyal üretip rekabet gücünü artırmak önemli olduğundan dolayı, tekstil ürünlerinin sonradan antibakteriyel madde ile işlem görerek üretilmesi giderek ilgi görmektedir.

Antibakteriyel bitim işlemi için kullanılan antimikrobiyel maddeler emdirme, çektirme, maksimum flotte aplikasyonu, köpükle aplikasyon, vakumla aplikasyon, püskürtme, aktarma, plazma ve kaplama yöntemlerinden biri kullanılarak tekstil materyaline aktarılır. Bu sayede mikroorganizmaların zararlı etkileri önlenir (Orhan, 2007).

Antibakteriyel etkisi olan materyallere taleplerin artması ve kullanılan antibakteriyel maddelerin ağır metaller içermesi, oluşturulan antibakteriyel materyaller üzerine şüpheler uyandırmaktadır. Yeryüzünde mikroorganizmaların etkilerini önleyen veya öldüren binlerce kimyasal madde bulunmaktadır. Fakat bunlardan birçoğu gümüş, civa, arsenik, kalay, kurşun gibi ağır metaller olduğu için insan ve çevreye karşı toksik etki meydana getirebilmektedir. Bu yüzden tekstil alanında kullanılacak antibakterityel madde yalnız mikroorganizmaların olumsuz etkilerini ortadan kaldırmakla kalmamalı, aynı zamanda insan ve çevreye karşı güvenli olmalıdır. Günümüzde antibakteriyel olarak kullanılan gümüş, çinko gibi ağır metaller, insan vücuduna karşı toksik etki yapabilmektedir ve zaman içinde vücutta birikmeleri çok ciddi hastalıklara yol açmaktadır. Bu yüzden doğal antibakteriyel bitkiler üzerine araştırmalar artmaktadır. Bu alanda meyan kökü, biberiye, şeker otu, kekik bitkileri üzerine çalışmalar yapıllmıştır (Uçar E. vd. 2015; Durmaz H. vd. 2018) .

Vitaceae familyasından olan üzüm (Vitis vinifera), dünya üzerinde genellikle kuzey yarım kürede 20-52 enlemleri arasında, güney yarım kürede ise 20-40 enlemleri arasında yetiştiriciliği uygun olan bir bitkidir (Çoban, 2010). Bu enlemlerde bulunan A.B.D., Şili, Güney Afrika, Avusturalya, Türkiye, Yunanistan ve İran önemli üzüm yetiştiricisi olan ülkelerdir.Üzüm, antioksidan, antimikrobiyel, antiinflamatuvar ve antikarsinojenik özellikleri olan çeşitli faydalara sahip bir meyvedir (Xia ve ark., 2010). Dünya üzüm üretiminin yaklaşık \%71'i şaraplık, \%27'si sofralık ve \%2'si ise kurutmalık olarak değerlendirilmektedi. 2018 TÜİK verilerine göre ülkemizde üretilen üzümün \%34'ü çekirdekli sofralık, \%16'sı çekirdeksiz sofralık, \%9'u çekirdekli kurutmalık, \%30'u çekirdeksiz kurutmalık, $\% 12$ 'si şaraplık olarak üretilmektedir.

Üzüm çekirdekleri üzüm ağırlığının yaklaşık \%20'sini meydana getirmektedir. Türkiye genelinde üzüm üzerine yapılan faaliyetlerde açığa çıkan yıllık üzüm çekirdeği miktarı yaklaşık 30.000 ton olarak tahmin edilmektedir (Akın ve Altındişli, 2010). Doğal kaynakların tükenmeye başlamasıyla hem ekonomik hem de çevresel açıdan her atığın değerlendirilmeye çalışıldığı günümüzde, giderek büyüyen geri dönüşüm zincirinde yerini almakta olan üzüm çekirdekleri, gün geçtikçe ülkemiz için büyük önem kazanmaktadır (Sevindik, 2016). 


\section{Materyal ve Metot}

\subsection{Kumaş}

Bu çalışmada kullanılacak olan tekstil materyali, gramaj1 $72 \mathrm{gr} / \mathrm{m}^{2}$, atkı sıllı̆̆ $30 \mathrm{tel} / \mathrm{cm}$, çözgü sıklığı 38 tel $/ \mathrm{cm}$ olan \%100 pamuklu kumaştır. Kumaşlara antibakteriyel özellik kazandırmak için üzüm çekirdeklerinin soxhlet cihazı ile ekstraksiyonu sonucu elde edilen fenolik bileşikler kullanılmıştır.

\subsection{Fenolik Bileşiklerin Eldesi}

Bu çalışmada evvela oda sıcaklığında kurutulan üzüm çekirdekleri öğütme makinası ile toz haline getirildikten sonra soxhlet cihazı ile ekstraksiyon işlemi yapılmıştır. Toz halindeki üzüm çekirdekleri 6 saat boyunca $60-80{ }^{\circ} \mathrm{C}$ 'de Soxhlet cihazında petrol eteri ile ekstrakte edilmiş üzüm çekirdeğinin yağı uzaklaştırılmıştır. Daha sonra 8 saat boyunca metanol-su-asetik asit $(90-9,5-0,5)$ ile ekstraksiyon işlemi yapılmıştır (Jayaprakasha ve ark., 2003). Ekstraksiyon işlemi sonucu elde edilen fenolik bileşiklerin tayini Yüksek Performanslı Sıvı Kromatografisi (HPLC) test cihazı ile tespit edilmiştir.

\subsection{Antibakteriyel Bitim İşlemi}

Üzüm çekirdeğinin Ekstraksiyon sonucu elde edilen $\% 50 \mathrm{mg} / \mathrm{ml}$ fenolik bileşik konsantrasyonunda, $200 \mathrm{~mL}$ emdirme banyosu hazırlanmıştır. \% 100 pamuklu kumaşa alınan flotte oranı \%90 olacak şekilde, silindir basıncı 2 bar ve hızı $2 \mathrm{~m} / \mathrm{dk}$ olan fluardda emdirilmiş̧ir (Rathinamoorthy ve Thilagavathi 2011). Daha sonra aplike işlemi yapılan kumaşlar ramözde 80 0C de 3 dk kurutulmuş, yine $100 \mathrm{0C}$ de $3 \mathrm{dk}$ boyunca ramözde fiske edilmiştir.

\subsection{AATCC 147 Antibakteriyel Test}

İşlem görmüş ve görmemiş kumaşların antibakteriyel aktivite testi AATCC 147 Test Metoduna göre gram negatif Escherichia coli bakterisine karşı yapılmıştır. $\mathrm{Bu}$ test metodunda uygulama yapılan kumaş ile uygulama yapılmayan kumaş karşıllaştırılarak antibakteriyel özellikte olup olamadığı tespit edilmektedir. Test edilen numunelerin hem altında hem de çevresinde bakteriler yok oluyorsa test edilen numune biyosidal antibakteriyel özelliktedir. Antibakteriyel etkinlik numune etrafindaki inhibisyon çapı ile ilişkilendirilmektedir. Test edilen numunenin sadece alt kısımlarında bakteri yok oluyorsa numunenin biyostatik bir antibakteriyel özellikte olduğuk değerlendirilmektedir. Bu yöntemle yapılan testler sonucunda kalitatif (nitel) sonuçlara elde edilmektedir.

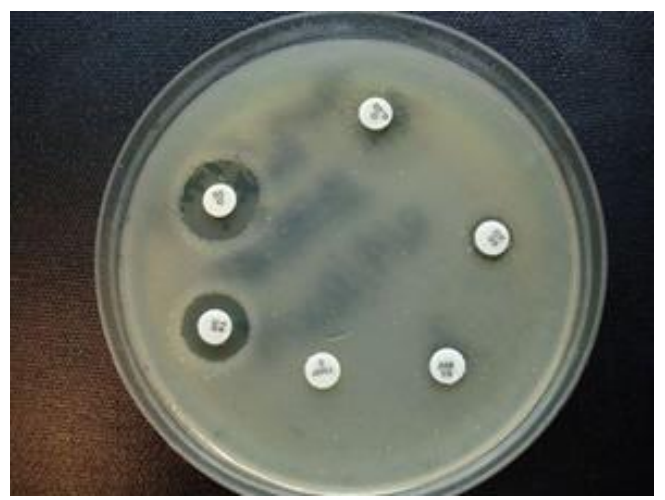

Şekil 2.1. AATCC 147 Antibakteriyel test için kullanılmış Müller - Hinton Agar Besiyeri

Nutrient broth agar olan petri kabına, bakteri yoğunluğu 1 McFarland'a ayarlanan konsantrasyon ile ekim yapılır. Antibakteriyel etkinliği araştırılmak istenen kumaş 2,5 x 5 cm ölçülerinde kesilerek aşılanan bakteri kolonileri ile temas edecek şekilde muller hinton agar besiyerine yerleştirilmiştir. Bakterilerin rahatlıkla üreyebildikleri ideal sıcaklık olan $37^{\circ} \mathrm{C}$ 'de 24 saat etüvde inkübasyona bırakılmıştır. 24 saatlik inkübasyondan sonra kumaş etrafında engelleme bölgesi oluşturmuşsa veya kumaş yüzeyinde bakteri üremesi mevcut değilse, numunenin antibakteriyel olduğu anlamına gelmektedir. Çalışmamızda kumaşların antibakteriyel özellik kazanıp kazanmadığı bu yöntem ile araştırılmıştır (Mucha vd. 2002).

\section{Araştırma Sonuçları ve Tartışma}

\section{1. Üzüm Çekirdeğindeki Fenolik Bileşiklerin HPLC ile tayini}

Ekstraksiyon işlemlerinin sonucunda elde edilen ekstraktta mevcut olan madde miktarının ve çeşidinin belirlemesinde yaygın olarak HPLC test yöntemi kullanılmaktadır. Akgün N. Ve Akgün M., 2006; Sabir vd., 2012; Lachman vd., 2013; Kostadinovic-Velickovska ve Mitrev, 2013; Fiori vd., 2014; Kreps vd., 2014; Assumpção vd., 2016 ve bir çok araştırmacı HPLC test yöntemini tercih etmişlerdir. Bu çalışmada da elde ettiğimiz ekstraktın içeriğinin belirlenmesinde bu test yöntemi kullanılmıştır. Fenolik maddelerin standart kromatogram değerleri Şekil 3.1' de verilmiştir. 


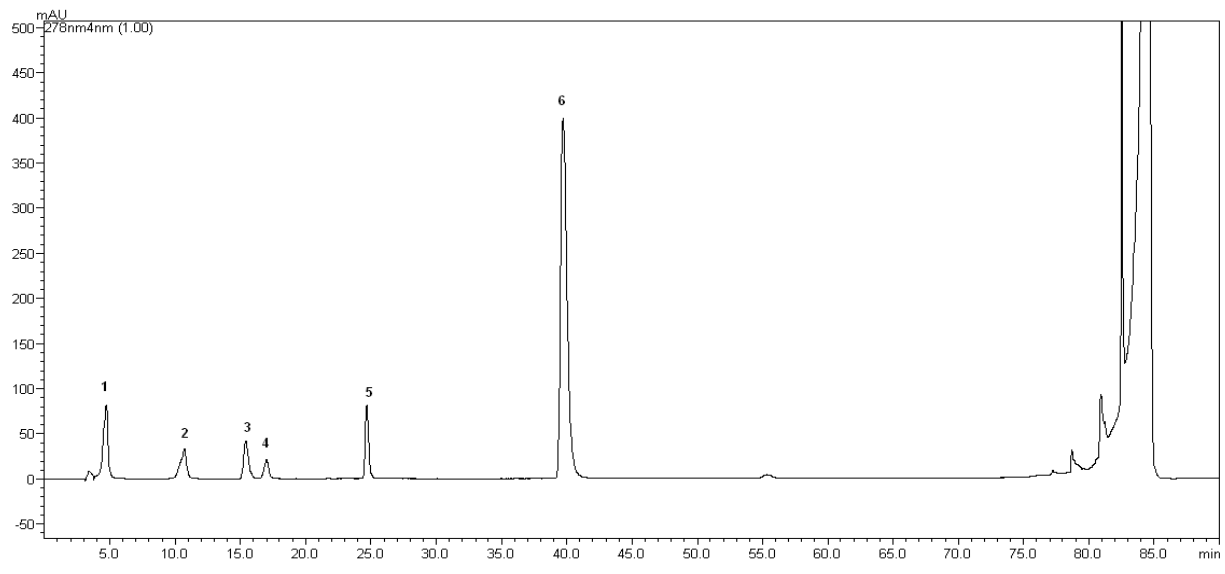

Şekil 3.1. Standart kromatogram (1: gallik asit, 2: kateşin, 3: kafeik asit, 4: epikateşin, 5: ferulik asit, 6: resveratrol)

Metanol ile ekstraksiyon işlemi yapılan üzüm çekirdeği ekstraktında HPLC analizi ile tespit edilen fenolik maddelerin kromatogram değerleri Şekil 3.2' deki kromatogram da verilmiştir. (1:gallic acid, 2:catechin, 3:caffeic acid, 4: epicatechin, 5:ferulic acid, 6: resveratrol)

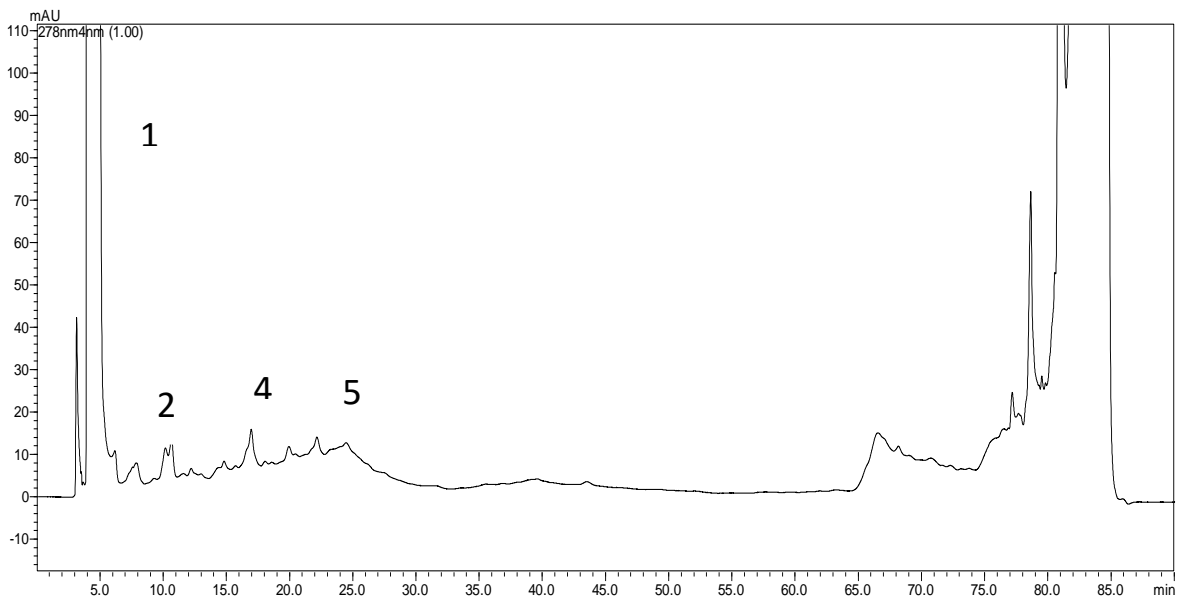

Şekil 3.2. Üzüm çekirdeği ekstraktı kromatogramı

Sonuçlar HPLC piklerinden alan olarak okunduktan sonra tüm fenolik bileşenler için çizilen standart kromatogram eğrilerinde yerlerine konularak hesaplanıp tablo halinde sunulmuştur. Üzüm çekirdeği ekstraktının içerdiği fenolik madde miktarı $(m g / g)$ Çizelge 3.1'de verilmiştir.

Tablo 3.1. Metanol İ̧̧erikli Çözgen İle Ekstrakte Edilen Üzüm Çekirdeğinin HPLC Sonucu (mg/g üzüm çekirdeği)

\begin{tabular}{|c|c|c|c|c|c|c|}
\hline Numune & Gallik Asit & Kateşin & $\begin{array}{c}\text { Kafeik } \\
\text { asit }\end{array}$ & Epikateşin & $\begin{array}{c}\text { Ferulik } \\
\text { asit }\end{array}$ & Resveratrol \\
\hline $\begin{array}{c}\text { Üzüm } \\
\text { Çekirdeği }\end{array}$ & 23,36 & 0,21 & $*$ & 0,27 & 0,08 & $*$ \\
\hline
\end{tabular}

*: tespit edilemedi

Analizi yapılan üzüm çekirdeğinde en fazla $23,36 \mathrm{mg} / \mathrm{g}$ ile gallik asit, kateşin $0,21 \mathrm{mg} / \mathrm{g}$, epikateşin $0,27 \mathrm{mg} / \mathrm{g}$ ve ferulik asit 0,08 $\mathrm{mg} / \mathrm{g}$ fenolik bileşiği tespit edilmiştir. Sonuçlarda toplamda üzüm çekirdeğinde $23,92 \mathrm{mg} / \mathrm{g}$ fenolik bileşik mevcut olduğu tespit edilmiştir.

Pastrana-Bonilla, E. vd. 2003 yılında yapmış oldukları çalışmada fenolik bileşiklerin toplam konsantrasyonu yaklaşık olarak, tohumda 2178,8 mg / g GAE, üzüm kabuğunda 374,6 mg / g GAE, üzümün etli kısmında 23,8 mg / g GAE ve yaprak kısmında 351,6 mg / g GAE olarak bulmuşlardır. Baydar vd. 2011 yılında üzüm çekirdeği ve üzüm kabuğu üzerine yapmış oldukları çalışmada, kalecik karası üzüm çekirdeği ekstraktında 242,53 mg 100 g-1 gallic acid, 517,13 mg 100 g-1 catechin ve 390,25 mg 100 g-1 epicatechin olduğunu tespit etmiştir. Bu sonuçlar bizim elde ettiğimiz sonuçlar ile örtüşmektedir. Birçok çalışmada da belirtildiği gibi üzümlerdeki 
fenolik bileşik miktarı üzüm çeşidine, toprak bileşimi, üzümün yetiştiği hava şartlarına (sıcaklık, nem), yetişme sürecinde maruz kaldığı mikroplara, mantarlara bağlı olarak değişmektedir (Bruno vd. 2007).

\subsection{Antibakteriyel Testlerin Sonucu}

$\mathrm{Bu}$ çalı̧mada AATCC 147 standardına göre yapılan antibakteriyellik testinde kumaşın alt tarafında ve çevresinde meydana gelen inhibisyon alanının büyüklüğü antibakteriyel özelliğin büyüklüğünü belirtmektedir. Antibakteriyel bitim işlemi uygulanan materyal çevresinde ve altında bakteri kolonilerinin görülmemesi beklenir. Antibakteriyel madde ile numune kumaş arasında kimyasal bağ oluşmuşsa, antibakteriyel ajanlar kumaş etrafına yayılamayacağı için kumaş etrafında bakteri kolonilerinin gözlenmesi beklenirken altında mevcut olmaması beklenir (Palamutcu vd. 2009). Bu yüzden kumaş etrafinda engelleme bölgesi oluşmayan testlerde kumaş pensetle kaldırılarak altında bakteriyal kolonilerin mevcut olup olmadığına bakılarak değerlendirmeler yapılmıştır. Bakteri yoğunluğu $1 \mathrm{McFarland'a} \mathrm{ayarlanarak} \mathrm{hazırlana} \mathrm{bakteri} \mathrm{kültürü} \mathrm{besiyere} \mathrm{aşılanmıştır.} \mathrm{Etkinliği} \mathrm{tespit} \mathrm{edilmek} \mathrm{istenen} \mathrm{ham} \mathrm{kumaş} \mathrm{ve} \mathrm{antibakteriyel}$ apre işlemi uygulanan kumaş numuneleri, aşllanan bakteri kolonileri ile temas edecek şekilde muller hinton agar besiyerine yerleştirilmiştir. Bakterilerin üremesi için gerekli olan besini petriden sağlarken, bir başka gereksinim olan sıcaklığ sağlamak için $37^{\circ} \mathrm{C}^{6}$ de 24 saat süre ile etüvde beklemeye alınmıştır. 24 saat sonrasındaki besiyerlerin görüntüsü Şekil 3.3 ve $3.4^{\prime}$ 'de verilmiştir.

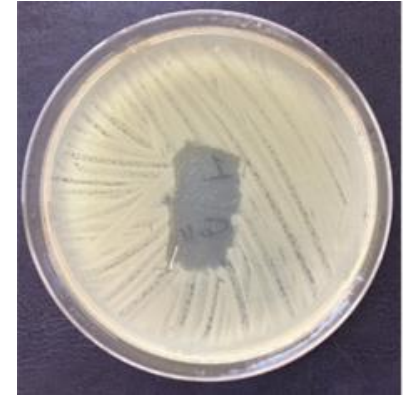

Şekil 3.3. Uygulama yapılmayan kumaşın antibakteriyel test sonucuna ait görüntü

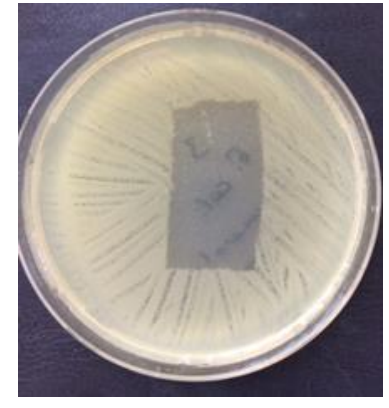

Şekil 3.4. Antibakteriyal bitim işlemi uygulanan kumaşın antibakteriyel test sonuçlarına ait görüntüleri

Yapılan antibakteriyel test sonucunda işlem görmemiş tekstil materyalinde bakteri üremesinin olduğu ve materyalin antibakteriyel özelliğinin olmadığı tespit edilmiştir. Uygulama yapılan tekstil materyalinin antibakteriyel test sonucunda ise etrafında inhibisyon çapı oluşmadığı görülmüştür. Fakat materyal altında bakteri üremesinin olmadığı tespit edilmiştir. Bu da bize yapmış olduğumuz uygulamanın kumaş üzerinde biyostatik olarak antibakteriyal özellik kazandırdı̆̆ını göstermektedir. Akaydın ve Kalkancı 2014 yılındaki çalışmalarında quaterner amonyum tuzu ile antibakteriyel apre işlemi yaptıkları numunelerin test sonuçlarında S. Aureus bakterisine karşı inhibisyon bölgesi oluşurken E. Coli bakterisine karşı oluşmadığını belirtmişlerdir. Fakat numunenin altında ise e. Coli bakteri mevcudiyetinin azaldığını belirtmişlerdir.

\section{Sonuç}

Pamuklu kumaşa antibakteriyel özelliği olan üzüm çekirdeği kullanılarak antibakteriyel özellik kazandırılabileceği araştırılmıştır. Ülkemizde yaklaşık olarak 30 bin ton üzüm çekirdeğinin atık olarak açığa çıktığı düşünülmektedir. Bu atık maddenin daha etkili ve verimli bir şekilde kullanılması çevre sorumluluğu ve ülke ekonomisine katma değer olarak dönüştürülmesi önem arz etmektedir. Şaraphane ve meyve suyu işletmelerinin atığı olan üzüm çekirdeğinde ortalama \% 7-20 civarında yağ, \%40 lifli yapı, \%7 tanen vb. karmaşık yapıdaki fenolikler, \%11 proteinler, \%7'sini su ve az miktarlarda şekerler ve mineraller bulunmaktadır (Rombaut, 2015). Üzüm çekirdeğinde bulunan bu biyoaktif bileşenler, antiülser, antikanserojen, antioksidan, antibakteriyel, antiviral, antimutajenik, antikolestrol özellikleriyle insan sağlığı açısından önemli bir yere sahiptir (Monagas vd., 2005).

Üzüm çekirdeği ekstraksiyonu içindeki fenolik bileşik tayini HPLC ile tayin edilmiştir. Pamuklu kumaşa ekstraksiyon içeriği ile hazırlanan reçete uygulanmıştır. Uygulama yapılan kumaş kurutma ve fikse işleminden sonra antibakteriyel testi AATCC 147 test metoduna göre yapılmıştır. Şekil 3.3.’de görüldüğü gibi işlem görmeyen kumaşın gram negatif olan E. Coli bakterisine karşı yapılan antibakteriyal testte, kumaş etrafında bakteriyal üremeyi engellediğini gösteren bir inhibisyon çapı oluşmamıştır. Aynı zamanda kumaşı kaldırdığımızda kumaş altında da bakteri kolonilerinin oluştuğu, üremenin meydana geldiği görülmektedir.

Antibakteriyal madde ile bitim işlemi uygulanan kumaşta (Şekil 3.4.) ise E. Coli bakteri türlerine karşı numune etrafında engelleme bölgesi oluşmamıştır. Fakat kumaşın pensetle kaldırılıp altına bakıldığında kumaş altında bakteri üremesinin olmadığı görülmektedir. Bu durum bize uygulama yaptığımız antibakteriyal maddenin biyostatik olduğunu göstermektedir. Yani antibakteriyal etki materyal ile bakterinin teması ile sağlanmaktadır. Kumaş yüzeyinden salınım ile gerçekleşmemektedir. Nicel bir metot olan AATCC 100 antibakteriyal test metodu antibakteriyal etkinliğin belirlenmesi açısından daha ayrıntılı ve kesin bilgiler verecektir.

\section{Kaynakça}

Akaydın, M., Kalkancı, M. (2014). Hastane Giysisi Olarak Kullanılan Kumaşların Antibakteriyel Özellikleri Üzerine Bir Araştırma, SDU Journal of Science 9 (1): 20-34. 
Altınok,B.,U., (2008). Tekstil Yüzeylerinin AntiBakteriyel Özelliklerinin Araştırılması. Yüksek Lisans Tezi, Süleyman Demirel Üniversitesi Fen Bilimleri Enstitüsü, Isparta, 204s

Baydar, N. G., Babalık, Z., Türk, F. H., Çetin E. S. (2011). Phenolic Composition and Antioxidant Activities of Wines and Extracts of Some Grape Varieties Grown in Turkey, Journal of Agricultural Sciences, 17: 67-76.

Bruno, G.; Sparapano, L. (2007). Effects of three esca-associated fungi on Vitis vinifera L : V. Changes in the chemical and biological profile of xylem sap from diseased cv. Sangiovese vines. Physiol. Mol. Plant Pathol, 71, 210-229.

Çoban H., (2010). Dünya Sofralık Üzüm Ticareti ve Bazı Önemli Üzüm Çeşitleri, 2010 Yılı Bahçe Bitkileri Grubu Bölge Bilgi Alışveriş Toplantısı Bildirileri Yayın No :139, s 60-68, Çanakkale.

Durmaz H., Hülül M., Celık H. (2018). Meyan (Glycyrrhiza glabra L.) Bitkisinin Antibakteriyel ve Antioksidan Aktiviteleri, Harran Üniversitesi Veterinerlik Fakültesi Dergisi, 37-41.

Jayaprakasha, G., Selvi, T., \& Sakarıah, K. (2003). Antibacterial and antioxidant activities of grape Vitis vinifera seed extracts. Food Research International, 36(2), 117-122.

Monagas, M., Bartolome, B., Gomez-Cordoves, C. (2005). Updated knowledge about the presence of phenolic compounds in wine. Critical Reviews in Food Science and Nutrition, 45(2), 85-118.

Mucha, H., Hofer, D., Abfalg, S., Swerev, M., (2002). Antimicrobial Finishes and Modifications. Melliand International, 8:148-151.

Orhan, M., (2007). Pamuk, Poliamid Ve Poliester Esaslı Tekstil Materyallerinde Antimikrobiyal Bitim Uygulamaları Üzerine Bir Araştırma, Bursa, Fen Bilimleri Enstitüsü, Doktora Tezi Uludağ Üniversitesi.

Palamutcu, S., Şengül, M., Devrent, N., Keskin, R., Hasçelik, B., (2008). Bazı Antimikrobiyal Maddelerin \% 100 Pamuklu Kumaslar Üzerindeki Mikrobiyolojik Etkinliği ve Kumaş Parametreleri Üzerindeki Etkilerinin Araştırılması. 106M338 no'lu Tübitak projesi, Denizli.

Pastrana-Bonilla, E.; Akoh, C.C.; Sellappan, S.; Krewer, G. (2003). Phenolic content and antioxidant capacity of muscadine grapes. J. Agric. Food Chem., 51, 5497-4503.

Rathinamoorthy, R., Thilagavathi, G., (2011). Antimicrobial and in-Vitro Drug Release Studies of Microencapsulated Terminalia Chebula Extract Finished Fabric. International Journal of Pharmacy and Life Sciences, 2(10), 1147-1153.

Rombaut, N., Savoire, R., Thomasset, B., Castello, J., Van Hecke, E., Lanoisellè, J-L., (2015). Optimization of oil yield and oil total phenolic content during grapeseed cold screw pressing. Ind Crop Prod 63: 26-33.

Sarıçam, A., (2014). Üzüm Çekirdeği Ekstraktlarının Antioksidan Ve Antimikrobiyal Özelliklerinin Belirlenmesi, Yüksek Lisans Tezi, Sakarya Üniversitesi Fen Bilimleri Enstitüsü, Sakarya.

Sevindik, O., Selli, S., (2016). Üzüm Çekirdeklerinin Temel Biyoaktif Bileşenleri, Çukurova Tarım Gıda Bil. Der., $31(2)$ : 9-16.

Süpüren, G., Çay, A., Kanat, E., Tarakçığlu, I., (2006). Antimikrobiyal Lifler. Tekstil ve Konfeksiyon Dergisi, sayı:2, 80-89.

Uçar E., Odabas Köse E., Özyiğit Y. Turgut K., (2015). Bazı Tıbbi ve Aromatik Bitkilerde Esansiyel Yağların Antimikrobiyal Aktivitelerinin Belirlenmesi, Süleyman Demirel Üniversitesi Ziraat Fakültesi Dergisi, say1: 10 (2):118-124.

Xıa, E.-Q., Deng, G.-F., Guo, Y.-J., \& Li, H.-B. (2010). Biological activities of polyphenols from grapes. International Journal of Molecular Sciences, 11(2), 622- 646. 